\title{
Genome-wide identification of differentially expressed genes under water deficit stress in upland cotton (Gossypium hirsutum L.)
}

\author{
Wonkeun Park', Brian E Scheffler ${ }^{2}$, Philip J Bauer ${ }^{1}$ and B Todd Campbell ${ }^{*}$
}

\begin{abstract}
Background: Cotton is the world's primary fiber crop and is a major agricultural commodity in over 30 countries. Like many other global commodities, sustainable cotton production is challenged by restricted natural resources. In response to the anticipated increase of agricultural water demand, a major research direction involves developing crops that use less water or that use water more efficiently. In this study, our objective was to identify differentially expressed genes in response to water deficit stress in cotton. A global expression analysis using cDNA-Amplified Fragment Length Polymorphism was conducted to compare root and leaf gene expression profiles from a putative drought resistant cotton cultivar grown under water deficit stressed and well watered field conditions.

Results: We identified a total of 519 differentially expressed transcript derived fragments. Of these, 147 transcript derived fragment sequences were functionally annotated according to their gene ontology. Nearly 70 percent of transcript derived fragments belonged to four major categories: 1) unclassified, 2) stress/defense, 3) metabolism, and 4) gene regulation. We found heat shock protein-related and reactive oxygen species-related transcript derived fragments to be among the major parts of functional pathways induced by water deficit stress. Also, twelve novel transcripts were identified as both water deficit responsive and cotton specific. A subset of differentially expressed transcript derived fragments was verified using reverse transcription-polymerase chain reaction. Differential expression analysis also identified five pairs of duplicated transcript derived fragments in which four pairs responded differentially between each of their two homologues under water deficit stress.

Conclusions: In this study, we detected differentially expressed transcript derived fragments from water deficit stressed root and leaf tissues in tetraploid cotton and provided their gene ontology, functional/biological distribution, and possible roles of gene duplication. This discovery demonstrates complex mechanisms involved with polyploid cotton's transcriptome response to naturally occurring field water deficit stress. The genes identified in this study will provide candidate targets to manipulate the water use characteristics of cotton at the molecular level.
\end{abstract}

\section{Background}

Predicted world population growth will require more food, feed, and fiber production. Intermittent drought and shortages of water supply negatively impact crop productivity and are predicted to occur more frequently in future agricultural systems [1-3]. In future agricultural systems, an increase in crop productivity must also be accompanied by a reduced environmental impact of

\footnotetext{
* Correspondence: todd.campbell@ars.usda.gov

${ }^{1}$ USDA-ARS, Coastal Plains Soil, Water and Plant Research Center, Florence, SC, USA

Full list of author information is available at the end of the article
}

production on natural resources [4]. Therefore, to increase productivity while maintaining adequate water resources, it is necessary to understand the mechanisms plants use to cope with water deficit stress [5]. There have been two general efforts towards more sustainable and water use efficient agricultural production. One effort is represented by breeding and genetic engineering $[1,6,7]$. Another effort is focused on the improvement of agricultural practices such as tillage and irrigation systems [8-10]. To successfully pursue the breeding and genetic engineering approach, it is fundamental to understand plant responses to drought stress at the

\section{Biomed Central}

(c) Park et al.; licensee BioMed Central Ltd. This is an Open Access article distributed under the terms of the Creative Commons Attribution License (http://creativecommons.org/licenses/by/2.0), which permits unrestricted use, distribution, and reproduction in any medium, provided the original work is properly cited. 
molecular, cellular, and genetics levels. This understanding is critical, because drought tolerance is a quantitative trait influenced by a combination of regulatory pathways $[5,11]$.

Drought stress impacts a network of plant gene expression mechanisms that lead to the reprogramming of a variety of physiological and metabolic processes in accordance with stress response. Early studies primarily used model plant species to identify a wide spectrum of genes that are involved in different levels of metabolism, signal transduction, osmotic regulation, stress response, and gene regulation [12-14]. More recently, many plant gene expression profiling experiments, using a range of technical approaches, have been conducted on economically important crop plants to determine stress related expression signatures. For example, next generation sequencing technology (NGS) has been applied to provide global gene expression profiles of whole transcriptomes $[15,16]$. NGS expression studies are greatly facilitated by the availability of annotated genome sequence (reference or otherwise).

As an alternative to NGS, the cDNA-AFLP technique is a widely adopted gene expression profiling method. This is especially true for crop plants, such as cotton, that are awaiting whole genome- or whole transcriptome- sequence data. cDNA-AFLP profiling has proven to be a robust method to discover differentially expressed genes in a number of plant species [17-19]. With the advantage of no prerequisite reference genome sequence requirement, cDNA-AFLP has been used to understand regulation mechanisms under various biotic and abiotic stress conditions that influence patterns of global gene expression in diverse crop species [20-22].

Cotton, a warm climate crop of tremendous global economic importance, is known to contain intrinsic mechanisms that allow it to partially withstand water deficit- and heat-stresses by its deep and extensive root system and adaptive osmoregulation mechanisms $[23,24]$. However, as water deficit stress progressively continues, development and reproduction of cotton is severely affected, and the quality and yield of cotton fiber production is significantly reduced $[25,26]$. Therefore, for successful cotton fiber production, it is essential to understand proper management strategies between water demand, irrigation, and plant responses that are seasonally variable [27].

In cotton, there are several reports on the molecular regulatory mechanisms that orchestrate drought resistance using quantitative trait loci (QTL) mapping or by developing drought stress induced cDNA libraries [2830]. In addition, microarray gene expression profiling has been used in cotton tissues exposed to variable water deficit stress in a controlled environment growth condition [31]. However, microarray gene expression profiling is limited to ESTs or genes present on the microarray chip and may not provide a complete representation of differentially expressed genes.

Although genome sequencing data of many economically important crop species are widely available as full or high quality draft formats [32], the progress of cotton genome sequencing has been slow. Genome sequencing of an ancestral diploid genome (D) is near completion $[33,34]$. Once complete, the D-genome sequence will be useful as a platform for more comprehensive information on cultivated cotton's tetraploid genome [35].

In this study, our objective was to gain comprehensive insight into the water deficit stress-related gene expression profile in cotton grown under field conditions. To accomplish this, we used cDNA-AFLP to identify differentially expressed genes in the roots and leaves of a single cotton cultivar grown in a rain-fed, drought-prone field environment. From this large comparative analysis, fundamental experimental data illustrate complex mechanisms of gene expression in response to water
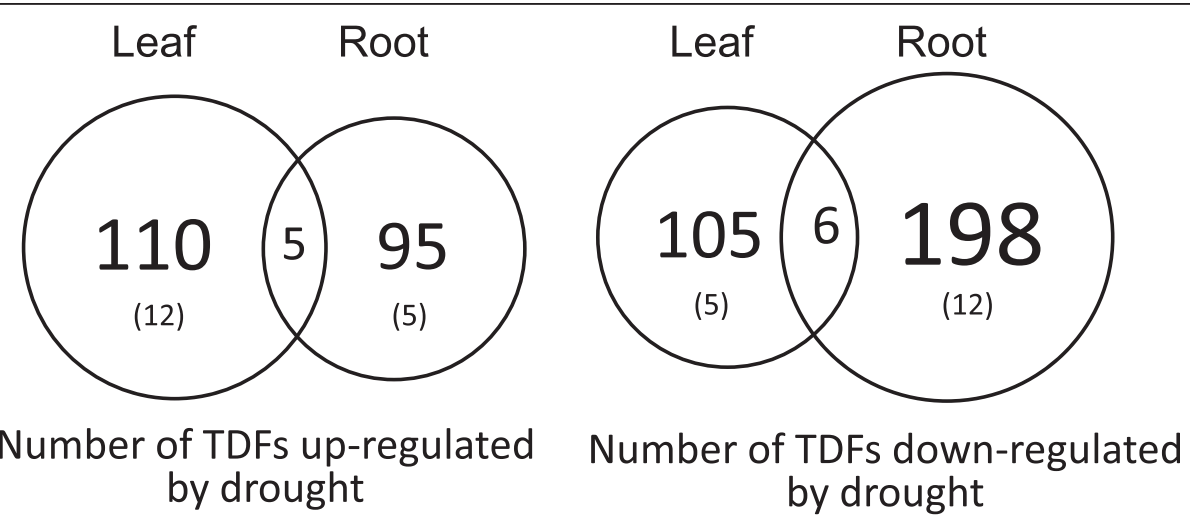

Figure 1 Diagrammatic distribution of differentially expressed TDFs in leaf and root tissues. Numbers in parentheses indicate reciprocally up- and down-regulated TDFs in two different tissues. 
deficit stress. This study should facilitate future efforts to improve the agricultural productivity of cotton and other crops under soil water deficit conditions.

\section{Results}

\section{Collection of CDNA-AFLP data sets}

Figure 1 summarizes the distribution of TDFs in leaf and root tissues. In total, 519 differentially expressed fragments (13\%) were detected among about 4,000 TDFs that demonstrated clear banding patterns produced by the LI-COR DNA analyzer. The TDFs ranged in fragment size from 50 to $700 \mathrm{bp}$. The remaining TDFs (87\%) showed equal expression in the tissues examined regardless of the water deficit stress applied. From the total 519 differentially expressed TDFs, 210 (40.5\%) showed increased expression and 309 TDFs (59.5\%) showed decreased expression. Among 210 TDFs with increased expression, 115 TDFs were from leaf tissue and 100 TDFs from roots. Five TDFs showed increased expression in both leaf and root tissues. Among 309 TDFs with reduced expression upon water deficit stress, 111 TDFs were from leaf tissue and 204 were from root tissue. Six TDFs showed reduced expression in both tissues. In addition to the 519 differentially expressed TDFs, 17 additional TDFs showed different expression patterns between leaf and root tissues (shown in parentheses in Figure 1). Expression of 12 of the 17 TDFs was induced in the leaf while being reduced in root tissue. The remaining five TDFs showed reduced expression in the leaf and induced expression in the root.

Since the cDNA-AFLP procedure uses a two selective nucleotide extension at the 3' terminus of each primer (See methods), there are 256 available primer combinations. In total, 64 primer combination covers onequarter of the transcriptome of interest in tissues tested. Although the total gene number of the cotton transcriptome is not clear, it is estimated that the tetraploid cotton genome contains over 70,000 genes [36]. Therefore, we estimate that our expression data represents approximately 17,500 genes.

\section{Sequence analysis and functional annotations}

Of the 519 differentially expressed fragments, 366 bands were excised, recovered, cloned, and sequenced. Three or four colonies from each excised band were bidirectionally sequenced, and a total of 1,440 clones were analyzed for sequence identity. Finally, 147 independent TDFs were verified by sequence analysis after evaluating the sequence products with expected size, the existence of two selective nucleotide extension, and clone reproducibility (Additional file 1, GenBank accession numbers JK512212- JK512358). Sizes of the fragments ranged from 177 to $680 \mathrm{bp}$ with the average length of $307 \mathrm{bp}$. Using criteria in the Gene Ontology annotation tool (http://www.geneontology.org/) [37], the functional annotation of TDFs was listed in ten categories (Figure 2). The majority of TDFs (68.8\%) grouped into four categories; 1) metabolism, 2) stress/defense mechanism, 3) gene regulation (transcription, translation, etc), and 4) unclassified. Twenty-five TDFs functioning in signal transduction (9.5\%) and transport (7.5\%) were also detected. Twenty-one TDFs (14.3\%) were assigned across four additional categories that included photosynthesis (5.4\%), cell growth/cellular structure (4.7\%), protein fate (2.7\%), and energy (1.4\%) (Figure 2 and Additional file 1). Among 36 unclassified TDFs, 16 belonged to conserved protein-coding genes, eight had sequence similarity to proteins of unknown function, and 12 did not show any sequence similarity to known protein sequences. One TDF (06E08) did not match any known protein or EST sequences in the NCBI database (Additional file 1). A cDNA library constructed from drought stressed G. arboreum, (a diploid cotton) indicated that $21.5 \%$ of clones had blast homology search similarity to unknown genes [29]. Similarly, our data showed 24.5\% of TDFs with similarity to unknown genes.

\section{Differentially expressed genes under water deficit stress}

Tissue specificity of annotated proteins is described in Additional file 1. Annotated proteins in the stress/defense category covered $18.4 \%$ (27 TDFs) of the total TDFs. Ten of these 27 TDFs coded for proteins related to the production of reactive oxygen species (ROS). Examples of ROSrelated proteins included glutathione $S$-transferase (GST), manganase superoxide dismutase (Mn-SOD)-like protein, glutathione peroxidase, mono-dehydroascorbate reductase, phosphoadenosine phosphosulfate reductase (Thioredoxin), aldo/keto reductase, 5'-adenylylsulfate reductase (Glutathione), and superoxide dismutase (SOD) copper

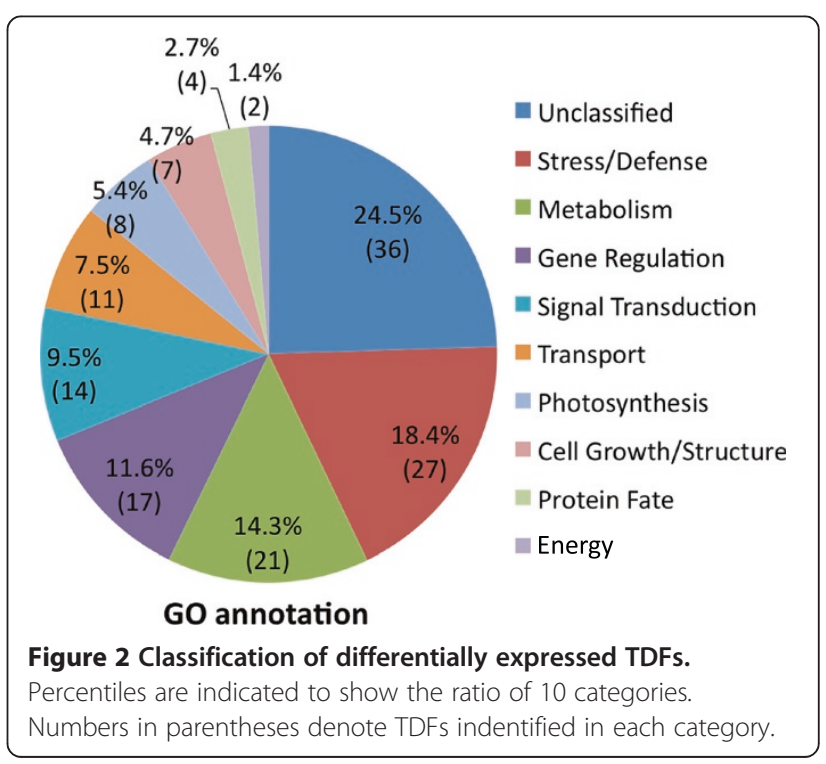


chaperone. Six of the 27 TDFs were annotated as heat shock proteins (HSP). Examples of annotated HSP included chloroplast HSP70.1-like proteins, HSP70, DnaJ HSP-like protein, and alpha-crystalline HSP. Also, of the 27 TDFs, two were annotated as alcohol dehydrogenase $(\mathrm{ADH})$ enzymes, two as drought-induced proteins, and seven TDFs with relationships to other stress/defense responses.

Fifteen TDFs in the metabolism category had similarity to predicted proteins participating in the biosynthesis pathways of fatty acids, amino acids, and sugars. This suggests active changes in the composition of biologically important macromolecules during water deficit stress. Interestingly, in the metabolism category, the number of TDFs differentially expressed under water deficit stress was $3 \mathrm{X}$ higher in root tissue than in leaf tissue (Figure 3). This suggests more dynamic metabolomic changes in root than in leaf.

Among the 17 gene-regulation categorized TDFs, eight coded for transcription factors and seven for translationrelated factors. The signal transduction category (14 TDFs, 9.5\%) consisted of four kinase, four phosphatase, and four GTP binding factors. Two TDFs coding for aquaporin proteins (PIP1;3 and PIP1;12) were identified in leaf and root tissues. Five cell-wall biosynthesisrelated genes were also identified (Additional file 1).
Figure 3 shows a comparison of up- (Figure 3A) and down-regulated (Figure 3B) TDFs in root and leaf tissues. Compared to leaf tissue, up-regulated TDFs were found more abundantly in the root across the five primary functional categories- unclassified, metabolism, stress/defense, signal transduction, and gene regulation. Down-regulation was more prominent in leaf tissue for stress/defense, signal transduction, and gene regulation. Down-regulation was more prominent in root tissue for metabolism, unclassified, and transport categories.

\section{Validation of expression pattern by RT-PCR}

RT-PCR was performed using specific primers for TDFs proportionally representative of each functional category. Since our primary focus was on stress response, more TDFs from the stress/defense category were included for RT-PCR analysis. Table 1 summarizes TDFs selected for expression analysis. For each TDF, all RT-PCR reactions produced products of the expected size according to sequence information. Sixty percent showed the same expression pattern as that collected from the cDNA-AFLP data. Although amplified using gene-specific primers, it is possible that expression of duplicated TDF copies negatively affected RT-PCR amplification. Given the relatively short average size of TDFs and the complexity of the tetraploid cotton genome, more sequence
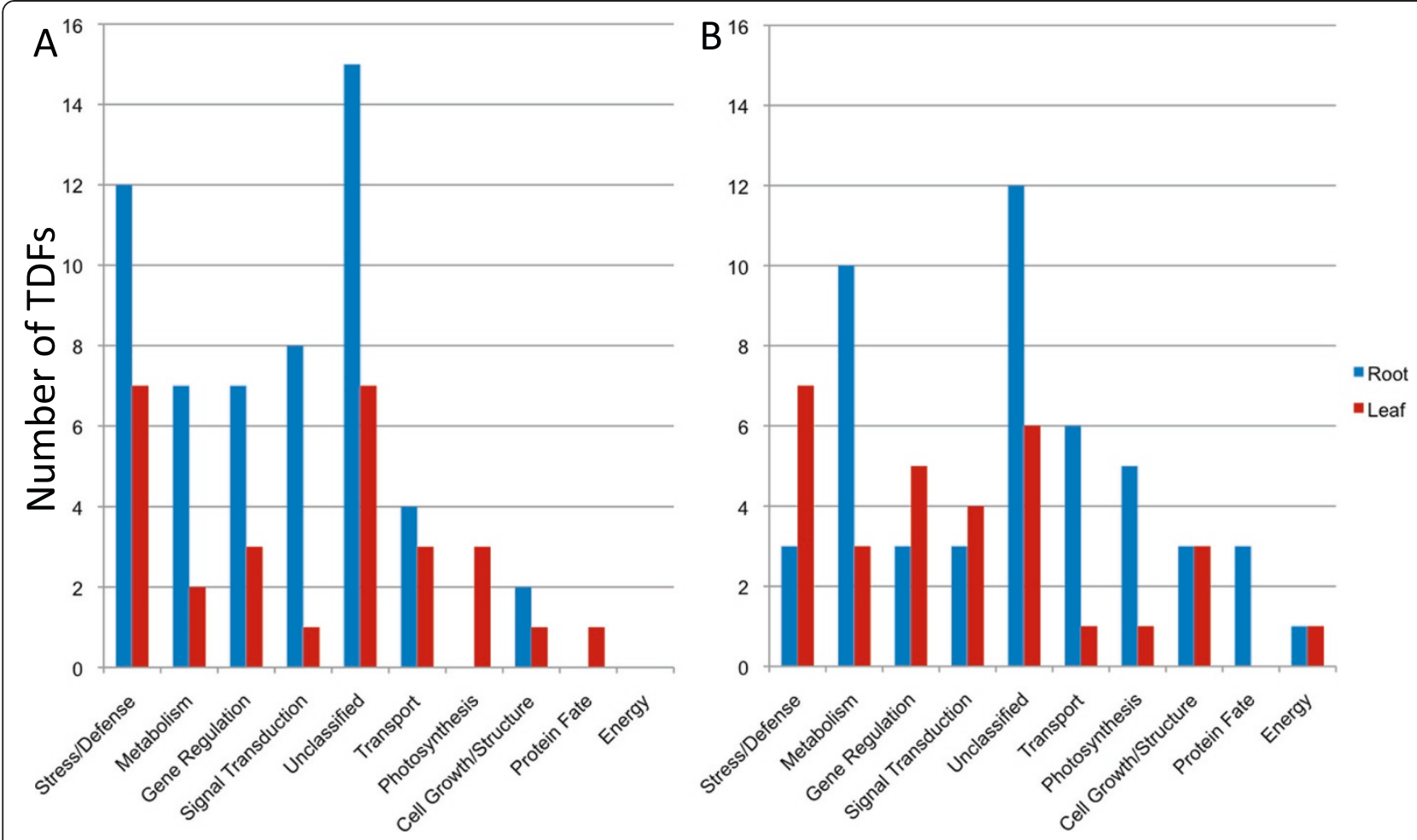

Figure 3 Comparison of TDF distribution in root and leaf tissues across functional categories: A) Up-regulated TDFs and B) Downregulated TDFs. 
Table 1 Summary of RT-PCR reactions performed for selected TDFs ${ }^{\mathrm{a}}$

\begin{tabular}{|c|c|c|c|c|c|c|}
\hline TDF ID & Description & Category & EST & CDNA-AFLP ${ }^{b}$ & Sizì (bp) & RT-PCR \\
\hline 02 C11 & Hypothetical & Unclassified & DT468917 & up R & 161 & $\mathrm{~N}$ \\
\hline $02 \mathrm{H} 11$ & Hypothetical & & DW510601 & up $R$ & 208 & Y \\
\hline $02 \mathrm{~A} 12$ & Hypothetical & & DW498397 & up $R$ & 244 & Y \\
\hline 06E08 & no homology & & $n a^{*}$ & up R & 186 & Y \\
\hline 06B01 & glycosyl transferase family 1 protein & & ES813597 & up L & 225 & $\mathrm{~N}$ \\
\hline 01D09 & nucleic acid binding protein/cold shock induced & Stress/Defense & ES820443 & up $R$ & 268 & Y \\
\hline 01B11 & chloroplast heat shock protein 70.1 & & DT572113 & up L up R & 176 & Y \\
\hline $02 \mathrm{D} 03$ & glutathione S-transferase & & DW495591 & up L & 320 & N \\
\hline 02A05 & Lea5-D/Drought induced & & DW228770 & up R & 233 & Y \\
\hline 02A09 & manganese superoxide dismutase-like protein & & DW226492 & $d n R$ & 209 & $\mathrm{~N}$ \\
\hline $03 \mathrm{E} 11$ & universal stress protein & & DW484973 & up R & 350 & N \\
\hline 04B09 & Hsp70 & & DW486235 & up $R$ & 275 & Y \\
\hline 02 C06 & phosphoethanolamine $\mathrm{N}$-methyltransferase & & DW238205 & up R & 505 & $\mathrm{~N}$ \\
\hline 07B12 & phosphoadenosine phosphosulfate reductase family protein & & EY197850 & up $R$ & 273 & Y \\
\hline $\mathrm{A} 04 \mathrm{H} 12$ & $\mathrm{Cu} / \mathrm{Zn} \mathrm{SOD}$ & & JG454758 & up $R$ & 338 & Y \\
\hline $03 \mathrm{~A} 07$ & beta-ketoacyl-ACP synthase II & Metabolism & DW238354 & up $R$ & 333 & Y \\
\hline $08 \mathrm{H} 05$ & ribose-5-phosphate isomerase & & DT556372 & up L & 227 & Y \\
\hline $08 \mathrm{D} 03$ & mannose-6-phosphate isomerase & & DW497531 & up $R$ & 175 & N \\
\hline $03 \mathrm{H} 01$ & MADS-box protein (AGL84) & Gene Regulation & ES839612 & up L & 151 & $\mathrm{~N}$ \\
\hline 02 F09 & translation initiation factor-like protein & & EX172706 & up R & 230 & Y \\
\hline 04 G11 & RAN2; GTP binding & Signal Transduction & ES827152 & $d n R$ & 180 & Y \\
\hline $08 \mathrm{H} 03$ & Lipoxigenase 3 & & DT567650 & up $R$ & 190 & Y \\
\hline 03 F02 & oligo Peptide transporter, putative & Transport & DW502711 & $d n R$ & 200 & $\mathrm{~N}$ \\
\hline 06 C03 & aquaporin $\mathrm{PIP} 1 ; 3 / 1 ; 4$ & & DQ402075 & up $R$ & 466 & Y \\
\hline \multirow[t]{2}{*}{ 06E09 } & aquaporin PIP1;12 & & GU998829 & up L & 313 & N \\
\hline & & & & $d n R$ & & \\
\hline $08 \mathrm{~A} 01$ & NITRATE TRANSPORTER1/PEPTIDE TRANSPORTER (POT/NAXT) family & & na & $d n R$ & 300 & Y \\
\hline 04D09 & Serine carboxypeptidase & Protein Fate & DT456670 & $d n R$ & 200 & Y \\
\hline $01 \mathrm{E} 10$ & Photosystem I reaction center subunit VI & Photosynthesis & EY197220 & up L & 189 & $\mathrm{~N}$ \\
\hline 07E12 & Cytochrome b6-f complex & & ES845215 & $d n L$ & 285 & $\mathrm{~N}$ \\
\hline 07E02 & hydrolase & Cell Growth/Structure & DT465622 & $d n L$ & 189 & $\mathrm{~N}$ \\
\hline A5B01 & Expansin & & DW494258 & $d n L$ & 278 & Y \\
\hline
\end{tabular}

${ }^{a}$ All reactions were replicated at least twice and two separate gel electrophoresis were performed per reaction.

${ }^{b}$ up and dn represent up-regulation and down-regulation, respectively in root $(R)$ and leaf $(L)$ tissues.

cexpected size from PCR amplification.

${ }^{d}$ RT-PCR results which correspond to CDNA-AFLP data $(\mathrm{Y})$ and do not $(\mathrm{N})$.

*Not available.

information is necessary to obtain enough sequence data for gene specific primer design and amplification. Comparing TDF sequences and EST sequences with adequate sequence coverage (if available) would allow unique sequence regions to be determined for better primer design.

\section{Gene duplication and water deficit stress}

The genomic and cytogenetic architecture of tetraploid cotton is a well-known example of gene duplication caused by whole genome duplication and polyploidization [38]. After collectively comparing analyzed TDF sequences, five pairs of duplicated TDFs were identified. As evidenced by different selective primer signatures, fragment sizes, and expression patterns, TDFs from each of five homologous pairs were shown to originate from highly similar but apparently distinct genes (Table 2). Since gene duplication (especially in polyploids) can contribute functional novelty in stress responses, we further analyzed homologous TDFs to have better insights 
Table 2 Homologous TDFs with high sequence similarity

\begin{tabular}{|c|c|c|c|c|c|c|c|c|c|c|}
\hline & \multicolumn{2}{|c|}{ Hypothetical 1} & \multicolumn{2}{|c|}{ Hypothetical 2} & \multicolumn{2}{|c|}{$\mathrm{M} \mathrm{PI}^{\mathrm{a}}$} & \multicolumn{2}{|c|}{$\mathrm{PIP} 1^{\mathrm{b}}$} & \multicolumn{2}{|c|}{ SOD CC } \\
\hline & 01 E01 & 02 C11 & $\mathrm{A} 02 \mathrm{CO} 3$ & $\mathrm{~A} 04 \mathrm{H} 02$ & 05 C11 & 08D03 & 06 C03 & 06E09 & A04A08 & A04G04 \\
\hline Msel/Taql & $\mathrm{AC} / \mathrm{TC}$ & $\mathrm{TC} / \mathrm{TC}$ & $\mathrm{TG} / \mathrm{CA}$ & $\mathrm{CT} / \mathrm{CA}$ & GT/AG & GT/AC & GT/AG & $\mathrm{TG} / \mathrm{AG}$ & $\mathrm{TC} / \mathrm{CA}$ & $\mathrm{AC} / \mathrm{CA}$ \\
\hline$b p^{\%}$ & 223 & 223 & 206 & 342 & 221 & 215 & 537 & 274 & 334 & 310 \\
\hline \multirow[t]{2}{*}{ Expression $^{\dagger}$} & $d n L$ & $d n R$ & $d n R$ & up R & up R & up R & up R & up L & up R & $d n L$ \\
\hline & dn R & & & & & & & dn R & & \\
\hline \multirow[t]{4}{*}{ Similarity to $A D$ genomes ${ }^{\S}$} & $100 \% \mathrm{~A}$ & $95 \% \mathrm{~A}$ & $98 \%$ Gh & $99 \%$ Gh & $98 \%$ Gh & $99 \%$ Gh & $99 \%$ A & $99 \%$ A & & \\
\hline & $98 \%$ D & $97 \%$ D & & & & & $98 \%$ D & $98 \%$ D & $100 \%$ Gh & $100 \%$ Gh \\
\hline & $100 \%$ Gh & $98 \%$ Gh & & & & & $99 \%$ Gh & $99 \%$ Gh & $100 \% \mathrm{~Gb}$ & $100 \% \mathrm{~Gb}$ \\
\hline & $100 \% \mathrm{~Gb}$ & $98 \%$ Gb & & & & & $99 \%$ Gb & $99 \%$ Gb & & \\
\hline
\end{tabular}

${ }^{a}$ Mannose 6 phosphate isomerase; ${ }^{b}$ plasma membrane intrinsic protein $1 ;{ }^{c}$ superoxide dismutase copper chaperone.

*Two nucleotide extensions at 3'-termini of each selective primer set.

${ }^{\%}$ Sizes of cDNA-AFLP bands.

${ }^{\dagger}$ up and dn represent up-regulation and down-regulation, respectively in root $(\mathrm{R})$ and leaf $(\mathrm{L})$ tissues.

${ }^{\S}$ Genomes from Gossypium arboreum (A), Gossypium raimondii (D), Gossypium hirsutum (Gh), and Gossypium barbadense (Gb).

into duplicated gene function under water deficit stress. These TDFs showed similarity to genes coding for proteins such as two hypothetical proteins (for 01E01/02 C11 and $\mathrm{A} 02 \mathrm{C} 03 / \mathrm{A} 04 \mathrm{H} 02)$, a mannose 6 phosphate isomerase (M6PI) enzyme (for 05 C11/08D03), a plasma membrane intrinsic protein 1 (PIP1) (for 06 C03/06E09), and a superoxide dismutase (SOD) copper chaperone (for A04A08/ A04G04).

Among them, PIP1-related TDFs (99\% identity with each other) belonged to a multi-gene aquaporin water channel membrane protein family in cotton [39]. These TDFs showed very high sequence similarity to GhPIP1;3, GhPIP1;4, GhPIP1;12 and GhPIP1;13 (E value $<$ 9E-174 for $06 \mathrm{C} 03$; < 6E-123 for 06E09 as shown by the multiple sequence alignment (Additional file 2)). According to the prediction of functional residues among aquaporin water channel proteins $[40,41]$, two amino acid substitutions (both Val-Ile conversions) between two TDFs do not affect functional properties. Moreover, these two non-synonymous substitutions belonged to the $4^{\text {th }}$ conserved transmembrane domain, $(\mathrm{V} / \mathrm{I}) \mathrm{GTF}(\mathrm{V} / \mathrm{I})$, that is found frequently in cotton EST sequences encoding the aquaporin PIP1 subgroup $[39,42]$. This points to the importance of either the Val or Ile at these two sites. Our differential expression revealed that an aquaporin TDF, 06 C03 is up-regulated in root by water deficit stress while a homologous TDF, 06E09 is up-regulated in leaf tissue and down-regulated in root tissue. This finding indicates the possible functional, tissue-specific diversification of duplicated PIP1 genes under water deficit stress. Duplicated TDFs from three other homologous pairs also showed differential expression patterns upon water deficit stress, whereas duplicated TDFs of M6PI showed the same pattern of expression (Table 2). These data indicate the possibility that products of duplicated genes might play roles in a tissue dependent manner and that regulatory elements controlling the expression of duplicated genes evolved along with polyploidization.

\section{Discussion}

\section{Molecular framework under water deficit}

Considering that drought-resistant cultivars are not readily available for commercial cotton production, more effort is required to identify or generate traits to withstand soil water deficit stress. In cotton production systems, rain-free periods occurring during reproductive growth are especially damaging. In this study, our objective was to understand a molecular architecture of water deficit stress at the level of gene expression by analyzing differentially expressed transcripts in the field during reproductive growth. Therefore, differentially expressed TDFs identified here can be considered genes functionally active (in case of up-regulation) or inactive (in case of down-regulation) at the stage of adaptation to naturally occurring water deficit stress. Our study revealed more than 500 transcripts with altered gene expression levels. The number of down-regulated genes was 1.5X higher than the number of up-regulated genes. Down-regulated genes occurred more frequently in root tissues. The majority of TDFs with altered expression belonged to functional categories including metabolism, stress/defense, signal transduction, and gene regulation as well as the category unclassified. This result corresponds well with previous findings of other species demonstrating transcriptome alteration under water deficit stress $[12,13]$.

In terms of cotton, a recent microarray expression profiling experiment conducted with plants in a greenhouse reported a total of 2,106 stress responsivetranscripts [31]. The majority of transcripts showed tissue specific expression and a higher number of stress 
responsive-transcripts were identified in leaf compared to root. In comparison, our study with field grown plants identified fewer stress responsive-transcripts (519), of which, 215 were leaf specific, 293 were root specific, and 11 were expressed in both leaf and root. The candidate gene targets identified in both studies require future work to determine their potential application to improve cotton water use.

Our expression data suggests the involvement of the ROS related defensive pathway since we identified 10 TDFs related to anti-oxidation mechanisms. The increased level of ROS, driven by water deficit stress, can affect cellular components that are oxidized partially or severely $[43,44]$. Therefore, it is critical that plants protect themselves from harmful oxidations with detoxifying mechanisms by using antioxidants and scavenging agents [45]. DST (Drought and Salt Tolerance), a previously unknown zinc finger protein, was found as a negative regulator of drought and salt stress by repressing $\mathrm{H}_{2} \mathrm{O}_{2}$ accumulation and stomatal closure in an abscisic acid (ABA)-independent manner [44]. In addition, recent studies on developmental and stress-induced cellular processes suggest that ROS and callose deposition are co-regulated, thereby controlling the cell wall matrix adjacent to the plasmodesmata for intercellular redox signal transduction [46]. In our study, one TDF (17-1A09) encoding a callose synthase-like family protein was isolated as a down-regulated gene and many ROS-related TDFs showed up regulation (seven TDFs) or downregulation (three TDFs). It is of interest to note that this plasmodesmata-related co-regulation of ROS and callose represents a cellular mechanism in the cotton fiber elongation process leading to water uptake following decreased osmotic potential in elongating fiber cells [47]. These findings highlight a possible interconnection between ROS and callose deposition in the areas adjacent to plasmodesmata that cotton employs in response to water deficit stress.

Previous studies have shown that phosphoethanolamine $N$-methyltransferase, vacuolar invertase, and aldo/ keto reductase (as identified in this study as TDFs 07B12, A05D02, and A04A09, respectively) are involved in water deficit stress-related defense mechanisms [4850]. When silenced, the decrease of phosphoethanolamine $N$-methyltransferase produced not only multiple growth defects but also temperature sensitive male sterility in Arabidopsis [49]. The vacuolar invertase was shown to be related to water deficit stress in maize [48]. Aldo/keto reductase catalyzes the detoxification reaction of reactive aldehyde groups generated by abiotic stresses thereby providing plants with stress tolerance [50].

It is well known in many plant species that ABA acts as a key hormone in the abiotic plant stress response $[51,52]$. Upon water deficit stress, stomata in leaves are closed and prevent water loss through transpiration. This process is believed to be regulated by ABA $[53,54]$. Interestingly, we did not identify any gene related to biosynthesis or action mechanisms of ABA nor genes involved in the regulation of stomata [55]. However, besides the function of ABA in stomatal closure, it was recently shown in Arabidopsis and tobacco that interactions possibly occur between water deficitresponsive proteins and HSP chaperones [56,57]. Under water deficit conditions, both HSP70 and HSP90 chaperones were recruited to control stomatal closure, thereby serving as machinery important for stomatal gating. The finding of HSP-coding TDFs also suggests the existence of the HSP related machinery in water deficit stress in cotton. In our study, five HSP-coding TDFs were up-regulated while only one showed down-regulation. Previously, a drought-related alpha-crystalline HSP was identified by differential screening from 10-d drought-stressed G. arboreum cotton seedlings and was effective in providing tetraploid cotton plants with drought stress tolerance when overexpressed [58,59]. The potential involvement of HSPrelated drought tolerance was also suggested recently in a microarray transcriptome analysis in drought-stressed cotton plants [31].

In accordance with transpiration, molecular mechanisms underlying water uptake and transport are pivotal throughout the plant body. There is accumulating evidence that addresses the relationship between aquaporins and transport of water in various physiological conditions including water deficit stress [60-64]. Aquaporins are frequently identified as water deficit stress responsive genes in diverse plant species [65-67]. In roots of drought stressed chickpea plants, members of the aquaporin gene family appeared up- and down-regulated suggesting that a complex regulation of water status governs plant growth and development through aquaporin activity under water deficit [68]. The identification of two homologous TDFs (06 C03 and 06E09) with similarity to members of the aquaporin water-channel protein family in this study (Table 2 and Additional file 1) indicate the possible involvement of cotton aquaporins under water deficit stressed leaf and root tissues. Recently, the identification of the large cotton aquaporin family illustrated their diverse function [39]. In addition to their fundamental role in intercellular transport of water molecules across the plant body, reports have shown the significance of aquaporins in facilitating leaf $\mathrm{CO}_{2}$ conductivity relevant to plant photosynthetic capacity [69-71]. However, the function of aquaporins in water deficit stress tolerance remains unclear as aquaporin genes have not been identified in water deficit stress QTL studies to date [72]. Therefore, more supportive and quantitative data need to follow. 
After sequencing 366 excised differentially expressed fragments, we functionally annotated 147 TDFs following sequence verification. Of the 147, we described a number of water deficit stress-responsive genes functionally relevant to metabolism, signal transduction, gene regulation, and stress/defense mechanisms in root and leaf tissues (Figure 3). In addition, homology searches using BlastX did not classify $24.5 \%$ of TDFs due to lack of sequence similarity to known proteins. Among those, twenty-seven unclassified TDFs were differentially expressed in root tissue. The abundance of unclassified TDFs identified in this study provide additional transcriptome coverage not represented in EST populations commonly used in microarray experiments. It was reported that unknown genes such as proteins with obscure functions (POF) cover more than $20 \%$ of each new genome sequenced with many being species specific [73].

In maize seedlings with water shortage, $5-11 \%$ of genes were differentially expressed across an array of genetically diverse inbred lines. Also, while many of the genes were not repeatedly identified in different maize lines, more than $40 \%$ of the cellular pathways were shared across all the lines examined [74]. In our study, a similar percentage of genes (13\%) showed expression level changes upon water deficit stress. Since the genotype in this study is believed to be drought tolerant, it would be interesting to determine if biological pathways highlighted in this study (for example, ROS-, or HSPrelated defense mechanisms) would appear in common across an array of cotton genotypes. Transcripts involving the HSP-containing functional group were also identified in a microarray based, water deficit stress response gene expression study using another cotton cultivar, FiberMax 989 [31]. The few water deficit stress-related cotton genes identified in the current study could be used in candidate gene-focused association mapping approaches to identify QTL under drought stress. This approach was previously shown to identify SNPs associated with ABA and sugar levels under water deficit [75].

\section{Implications of gene duplication in cotton abiotic stress response}

As evidenced by recent studies, it is becoming clearer that gene duplication has contributed to adaptive evolution and plant diversification that can lead to evolutionary novelty [76-78]. In our study, four pairs of duplicated genes including two PIP1 homologues were regulated spatially under water deficit stress (Table 2). The differential expression of two duplicated PIP1s did not appear to result from differences of deduced amino acid sequences (Additional file 2). Hence, it is of interest to elucidate factors that lead to the differential response of duplicated genes against stress. These responses can be controlled genetically, epigenetically, or by gene specific cis- or trans-elements [79]. Recent studies on genetic and epigenetic responses of plant genomes under environmental stimuli suggest that novel stress-induced genotypes such as methylation-sensitive polymorphisms can contribute to crop diversity that may lead to improvements in productivity [80]. In rice, drought stress-induced changes in genome-wide methylation patterns were evaluated using a methylation sensitive cDNA-AFLP method. This revealed a $12.1 \%$ site-specific methylation difference between a drought tolerant line (DK151) and its sensitive progenitor line (IR64) when stressed and showed methylation status was regulated tissue specifically [81]. Thus, water deficit responsive molecular changes presented in our study implicate important mechanisms of each gene or coordinated regulation of genes that should be targets of future study.

\section{Conclusions}

In response to field applied water deficit stress, we identified 519 differentially expressed TDFs. This global expression analysis generated sequence information for 147 TDFs and provided gene ontology, distribution of functional categories, and homologous genes. In accordance with data provided here, we highlight possible mechanisms by which cotton responds to water deficit stress. The combination of molecular changes in gene regulation and signal transduction results in increased activity of ROS-related defense mechanisms and HSPdriven protection machinery to provide cellular redox homeostasis and stabilization of functionally/structurally important proteins. A readily available cotton genome sequence will enhance our ability to understand the relationship between gene duplication/polyploidy and the functional, molecular adjustments cotton makes in response to water deficit stress and other environmental stresses.

\section{Methods}

\section{Plant materials}

During 2009, two 8-row plots (6 m row length and $96.5 \mathrm{~cm}$ row spacing) of cv. Siokra L-23 were grown at the North Carolina State University Sandhills Research Station near Jackson Springs, NC, USA on a uniformly deep, Candor sand soil with very low water holding capacity. Plots were subjected to irrigated and non-irrigated conditions, respectively, for 4 weeks during reproductive growth. Irrigation was applied supplemental to recorded rainfall weekly using above-ground drip irrigation as described by Campbell and Bauer [82]. Siokra L-23 is generally known to be tolerant to water deficit stress in molecular and physiological levels [83,84]. All plant measurements and tissue samples were obtained mid- 
day during the flowering period. On each sample date, to confirm differential plant water status, the water potential of uppermost fully expanded leaves was measured on three representative plants from each plot with a pressure bomb (Model 600, PMS Instrument Company, Albany, OR). From the same plants, leaf and root tissues were harvested and immediately frozen in liquid nitrogen for RNA isolation.

\section{RNA isolation, cDNA synthesis, and cDNA-AFLP}

Tissues collected from a single sample date with the greatest water potential difference between well-watered and water deficit stressed plants were used for all nucleic acid analyses. Average water potential of leaf tissue from well-watered and water deficit stressed plants was $-1.47 \pm 0.13 \mathrm{MPa}$ and $-2.58 \pm 0.34 \mathrm{MPa}$, respectively. Total RNA was isolated using the XT buffer system with the addition of chloroform/iso-amyl alcohol extraction and $\mathrm{LiCl}$ precipitation steps [85]. Isolation of total RNA and mRNA purification is described previously [39].

A cDNA template was synthesized as follows. First, poly(A) RNA was purified from $200 \mu \mathrm{g}$ of total RNA using a microPoly(A) Purist Kit (Ambion). After the treatment of DNase, $1 \mu \mathrm{g}$ of purified mRNA was used to generate first strand cDNA following the manufacturer's protocol (SuperScript III $1^{\text {st }}$ strand cDNA synthesis kit, Invitrogen) with no RNase $\mathrm{H}$ treatment. Doublestranded cDNA was synthesized using an E.coli DNA polymerase I (NEB) with RNase $\mathrm{H}$ (Invitrogen) at $16^{\circ} \mathrm{C}$ for 1 hour followed by an additional reaction for 1 hour at $22^{\circ} \mathrm{C}$ with T4 DNA ligase (NEB) treatment. After inactivation and clean-up, double-stranded cDNA template was digested with TaqI and MseI restriction endonucleases sequentially, ligated with two adaptors, and amplified with pre-amplification primer mix (MseI primer: 5'-GATGAGTCCTGAGTAA-3', TaqI primer: 5'GTAGACTGCGTACCGA-3'). After dilution (1:150) of pre-amplified DNA samples, selective amplification steps were performed with 64 combinations of eight $M s e I$ selective primers (5'-GATGAGTCCTGAGTAANN'-3') and eight IRDye 700-labeled TaqI selective primers (5'-/ 5IRD700/GTAGACTGCGTACCGANN'-3') for all four templates as indicated in the LI-COR cDNA-AFLP protocol. More detailed cDNA-AFLP procedures are described elsewhere $[19,86]$. Two separate denaturing polyacryamide gel electrophoresis (PAGE) gels were analyzed for each sample using a LI-COR 4300 DNA Analyzer; one for the preliminary differential expression profiling and the other for gel scanning and band excision. Gel scan images were produced using a LI-COR Odyssey Infrared Imaging System that can detect amplified fragments labeled with IRDye 700. Band excision and recovery of fragments were performed as recommended in the LI-COR manual. To verify technical reproducibility of the cDNA-AFLP reactions, pre-and selective amplification reactions were performed twice independently using three randomly chosen cDNA-AFLP primer sets and the image resolved on a $6.5 \%$ PAGE is provided in Additional file 3.

\section{Cloning, sequencing, and sequence analysis}

After recovery of individual TDFs from cDNA-AFLP, fragments were re-amplified with primers used for preamplification and subcloned into pCR-TOPO cloning vector systems (Invitrogen) following clean-up of PCR reaction products with a Wizard PCR clean-up kit (Promega). Three to four colonies from each band were bidirectionally sequenced. Details about cloning, sequencing, and RT-PCR amplification procedures have been described previously [39]. Sequence information of genespecific primers used for RT-PCR is available upon request. For the identity of sequenced TDFs, homology-based blast searches from the National Center for Biotechnology Information (NCBI, http://www.ncbi.nlm.nih.gov/) were performed, and predicted protein sequences and ESTs with highest similarity were annotated. Functional annotation of each TDF was also performed following the Gene Ontology tool [37]. When necessary, cotton assembly contig sequences were used for additional blast homology searches with a cotton 46 version that is available from the Comparative Evolutionary Genomics of Cotton web site (http://cottonevolution.info/). Alignment and assembly of sequences were processed using VectorNTI (Invitrogen) and ClustalW2 programs (http://www.ebi.ac.uk/Tools/ $\mathrm{msa} /$ clustalw2/).

\section{Additional files}

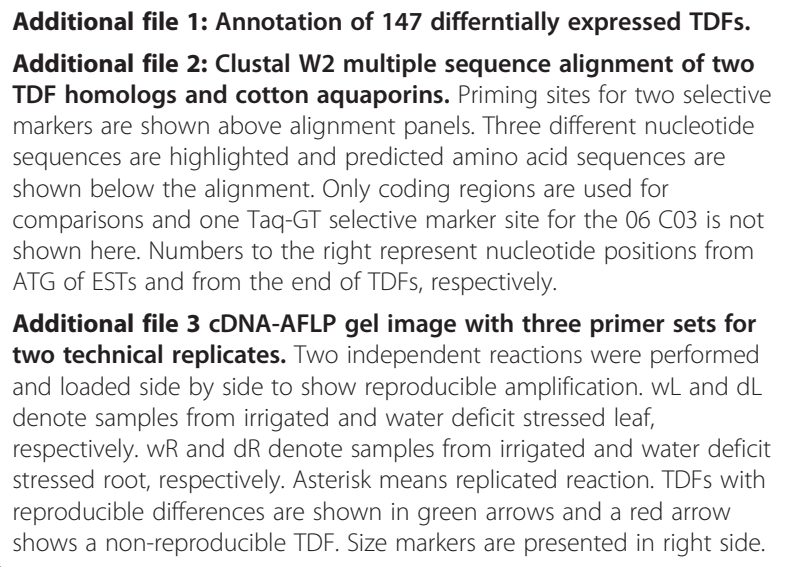

Additional file 3 cDNA-AFLP gel image with three primer sets for two technical replicates. Two independent reactions were performed and loaded side by side to show reproducible amplification. $\mathrm{WL}$ and $\mathrm{dL}$ denote samples from irrigated and water deficit stressed leaf,

respectively. $w R$ and $d R$ denote samples from irrigated and water deficit stressed root, respectively. Asterisk means replicated reaction. TDFs with reproducible differences are shown in green arrows and a red arrow

shows a non-reproducible TDF. Size markers are presented in right side.

\section{Abbreviations}

AFLP: Amplified fragment length polymorphism; RT-PCR: Reverse transcription-polymerase chain reaction; TDF: Transcript derived fragment; ROS: Reactive oxygen species; HSP: Heat shock protein. 


\section{Authors' contributions}

WP participated in the experimental design, performed experiments, analyzed data, and wrote the manuscript. BES performed DNA sequencing and participated in writing the manuscript. PJB participated in the experimental design and writing the manuscript. BTC participated in the experimental design, supervised all procedures, analyzed data and wrote the manuscript. All authors read and approved the final manuscript.

\section{Acknowledgements}

This research project was supported by funding from CRIS No. 6657-21000006-00D of the U.S. Department of Agriculture and a grant from Cotton Incorporated. Authors acknowledge assistance from Dr. Paxton Payton for the RNA isolation protocol, Drs. Joshua Udall and Martin Wubben for critically reviewing this manuscript, Drs. Michel Claverie and Jean Marc Lacape for the CDNA-AFLP protocol, Fanny Liu for DNA sequencing, and Dr. Greg Constable for supplying cotton seeds. We acknowledge Mr. Jeff Chandler and North Carolina State University Sandhills Research Station staff for providing excellent technical field plot support. We also thank Ernie Strickland, Kendreal Wingate, and Bobby Fisher for their technical assistance. Mention of trade names or commercial products in this publication is solely for the purpose of providing specific information and does not imply recommendation or endorsement by the U.S. Department of Agriculture.

\section{Author details}

${ }^{1}$ USDA-ARS, Coastal Plains Soil, Water and Plant Research Center, Florence, SC, USA. ${ }^{2}$ USDA-ARS, MSA Genomics Laboratory, Stoneville, MS, USA.

Received: 23 September 2011 Accepted: 10 May 2012 Published: 15 June 2012

\section{References}

1. Chaves MM, Oliveira MM: Mechanisms underlying plant resilience to water deficits: prospects for water-saving agriculture. J Exp Bot 2004, 55(407):2365-2384

2. Fedoroff NV, Battisti DS, Beachy RN, Cooper PJ, Fischhoff DA, Hodges CN, Knauf VC, Lobell D, Mazur BJ, Molden D, et al: Radically rethinking agriculture for the 21st century. Science 2010, 327(5967):833-834.

3. Long SP, Ort DR: More than taking the heat: crops and global change. Curr Opin Plant Biol 2010, 13(3):241-248.

4. Zhao M, Running SW: Drought-induced reduction in global terrestrial net primary production from 2000 through 2009. Science 2010, 329(5994):940-943.

5. Morison JIL, Baker NR, Mullineaux PM, Davies WJ: Improving water use in crop production. Phil Trans R Soc B 2008, 363:639-658.

6. Stiller WN, Read JJ, Constable GA, Reid PE: Selection for water use efficiency traits in a cotton breeding program:cultivar differences. Crop Sci 2005, 45:1107-1113.

7. Campbell BT, Chee PW, Lubbers E, Bowman DT, Meredith WR, Johnson JM, Fraser DE: Genetic Improvement of the Pee Dee Cotton Germplasm Collection following Seventy Years of Plant Breeding. Crop Sci 2011, 51:955-968.

8. Bhattarai SP, McHugh AD, Lotz G, Midmore DJ: The response of cotton to subsurface drip and furrow irrigation in a vertisol. Exp Agric 2006, 42:29-49.

9. Truman CC, Strickland TC, Potter TL, Franklin DH, Bosch DD, Bednarz CW: Variable rainfall intensity and tillage effects on runoff, sediment, and carbon losses from a loamy sand under simulated rainfall. J Environ Qual 2007, 36(5):1495-1502.

10. Bauer PJ, Fortnum BA, Frederick JR: Cotton responses to tillage and rotation during the turn of the century drought. Agron J 2010, 102(4):1145-1148.

11. Ahuja I, de Vos RC, Bones AM, Hall RD: Plant molecular stress responses face climate change. Trends Plant Sci 2010, 15(12):664-674.

12. Seki M, Narusaka M, Ishida J, Nanjo T, Fujita M, Oono Y, Kamiya A, Nakajima M, Enju A, Sakurai T, et al: Monitoring the expression profiles of 7000 Arabidopsis genes under drought, cold and high-salinity stresses using a full-length cDNA microarray. Plant J 2002, 31(3):279-292

13. Rabbani MA, Maruyama K, Abe H, Khan MA, Katsura K, Ito Y, Yoshiwara K, Seki M, Shinozaki K, Yamaguchi-Shinozaki K: Monitoring expression profiles of rice genes under cold, drought, and high-salinity stresses and abscisic acid application using CDNA microarray and RNA gel-blot analyses. Plant Physiol 2003, 133(4):1755-1767.

14. Umezawa T, Fujita M, Fujita Y, Yamaguchi-Shinozaki K, Shinozaki K: Engineering drought tolerance in plants: discovering and tailoring genes to unlock the future. Curr Opin Biotechnol 2006, 17(2):113-122.

15. Cnudde F, Hedatale V, de Jong H, Pierson ES, Rainey DY, Zabeau M, Weterings K, Gerats T, Peters JL: Changes in gene expression during male meiosis in Petunia hybrida. Chromosome Res 2006, 14(8):919-932.

16. Bellin D, Ferrarini A, Chimento A, Kaiser O, Levenkova N, Bouffard P, Delledonne $\mathrm{M}$ : Combining next-generation pyrosequencing with microarray for large scale expression analysis in non-model species. BMC Genomics 2009, 10:555.

17. Bachem CW, van der Hoeven RS, de Bruijn SM, Vreugdenhil D, Zabeau M, Visser RG: Visualization of differential gene expression using a novel method of RNA fingerprinting based on AFLP: analysis of gene expression during potato tuber development. Plant J 1996, 9(5):745-753.

18. Akihiro T, Umezawa T, Ueki C, Lobna BM, Mizuno K, Ohta M, Fujimura T: Genome wide CDNA-AFLP analysis of genes rapidly induced by combined sucrose and ABA treatment in rice cultured cells. FEBS Lett 2006, 580(25):5947-5952.

19. Vuylsteke M, Peleman JD, van Eijk MJ: AFLP-based transcript profiling (CDNA-AFLP) for genome-wide expression analysis. Nat Protoc 2007, 2(6):1399-1413.

20. Durrant WE, Rowland O, Piedras P, Hammond-Kosack KE, Jones JD: CDNAAFLP reveals a striking overlap in race-specific resistance and wound response gene expression profiles. Plant Cell 2000, 12(6):963-977.

21. Dubos C, Plomion C: Identification of water-deficit responsive genes in maritime pine (Pinus pinaster Ait.) roots. Plant Mol Biol 2003, 51(2):249-262.

22. Wang X, Tang C, Zhang G, Li Y, Wang C, Liu B, Qu Z, Zhao J, Han Q, Huang $L$, et al: CDNA-AFLP analysis reveals differential gene expression in compatible interaction of wheat challenged with Puccinia striiformis $f$. sp. tritici. BMC Genomics 2009, 10:289.

23. Ackerson RC, Hebert RR: Osmoregulation in cotton in response to water stress: I. Alterations in photosynthesis, leaf conductance, translocation, and ultrastructure. Plant Physiol 1981, 67(3):484-488.

24. Grimes DW, Yamada H: Relation of cotton growth and yield to minimum leaf water potential. Crop Sci 1982, 22:134-139.

25. Cothren J: Physiology of the Cotton Plant. In Cotton: Origin, History, Technology, and Production. Edited by Smith CW, Cothren J.: New York, New York: Wiley; 1999:207-268.

26. Bradow JM, Davidonis GH: Effects of environment on fiber quality. In Physiology of cotton. Edited by Stewart JM, Oosterhuis DM, Heitholt JJ, Mauney JR.: Heidelberg, Germany: Springer; 2010:229-245.

27. Martin EC, Stephens W, Wiedenfeld R, Bittenbender HC, Beasley JPJ, Moore JM, Neibling H, CGallian JJ: Sugars, oil, \& fiber crops. In Irrigation of agricultural crops. 2nd edition. Edited by Lascano RJ, Sojka RE.: Madison, Wisconsin: ASA-CSSA-SSSA; 2007:279-335. vol. 30.

28. Saranga Y, Menz M, Jiang CX, Wright RJ, Yakir D, Paterson AH: Genomic dissection of genotype $x$ environment interactions conferring adaptation of cotton to arid conditions. Genome Res 2001, 11(12):1988-1995.

29. Zhang L, Li FG, Liu CL, Zhang CJ, Zhang XY: Construction and analysis of cotton (Gossypium arboreum L.) drought-related cDNA library. BMC Res Notes 2009, 2:120.

30. Levi A, Paterson AH, Cakmak I, Saranga Y: Metabolite and mineral analyses of cotton near-isogenic lines introgressed with QTLs for productivity and drought-related traits. Physiol Plant 2011, 141(3):265-275.

31. Payton P, Kottapalli KR, Kebede H, Mahan JR, Wright RJ, Allen RD: Examining the drought stress transcriptome in cotton leaf and root tissue. Biotechnol Lett 2011, 33(4):821-828

32. Feuillet C, Leach JE, Rogers J, Schnable PS, Eversole K: Crop genome sequencing: lessons and rationales. Trends Plant Sci 2011, 16(2):77-88.

33. Taliercio E, Allen RD, Essenberg M, Klueva N, Nguyen H, Patil MA, Payton P, Millena AC, Phillips AL, Pierce ML, et al: Analysis of ESTs from multiple Gossypium hirsutum tissues and identification of SSRs. Genome 2006, 49(4):306-319.

34. Udall JA, Swanson JM, Haller K, Rapp RA, Sparks ME, Hatfield J, Yu Y, Wu Y, Dowd C, Arpat AB, et al: A global assembly of cotton ESTs. Genome Res 2006, 16(3):441-450

35. Paterson AH, Rong J, Gingle AR, Chee PW, Dennis ES, Llewellyn D, Dure LS III, Haigler C, Myers JO, Peterson DG, et al: Sequencing and Utilization of the Gossypium Genomes. Tropical Plant Biol 2010, 3:71-74. 
36. Guo W, Cai C, Wang C, Zhao L, Wang L, Zhang T: A preliminary analysis of genome structure and composition in Gossypium hirsutum. BMC Genomics 2008, 9:314.

37. Ashburner M, Ball CA, Blake JA, Botstein D, Butler H, Cherry JM, Davis AP, Dolinski K, Dwight SS, Eppig JT, et al: Gene ontology: tool for the unification of biology. The Gene Ontology Consortium. Nat Genet 2000, 25(1):25-29.

38. Flagel LE, Wendel JF: Gene duplication and evolutionary novelty in plants. New Phytol 2009, 183(3):557-564.

39. Park W, Scheffler BE, Bauer PJ, Campbell BT: Identification of the family of aquaporin genes and their expression in upland cotton (Gossypium hirsutum L.). BMC Plant Biol 2010, 10:142.

40. Froger A, Tallur B, Thomas D, Delamarche C: Prediction of functional residues in water channels and related proteins. Protein Sci 1998, 7(6):1458-1468.

41. Maurel C, Verdoucq L, Luu DT, Santoni V: Plant aquaporins: membrane channels with multiple integrated functions. Annu Rev Plant Biol 2008, 59:595-624

42. Yang Z, Wu Y, Li Y, Ling HQ, Chu C: OsMT1a, a type 1 metallothionein, plays the pivotal role in zinc homeostasis and drought tolerance in rice. Plant Mol Biol 2009, 70(1-2):219-229.

43. Foyer $\mathrm{CH}$, Noctor $\mathrm{G}$ : Redox homeostasis and antioxidant signaling: a metabolic interface between stress perception and physiological responses. Plant Cell 2005, 17(7):1866-1875

44. Huang XY, Chao DY, Gao JP, Zhu MZ, Shi M, Lin HX: A previously unknown zinc finger protein, DST, regulates drought and salt tolerance in rice via stomatal aperture control. Genes Dev 2009, 23(15):1805-1817.

45. Jubany-Mari T, Munne-Bosch S, Alegre L: Redox regulation of water stress responses in field-grown plants. Role of hydrogen peroxide and ascorbate. Plant Physiol Biochem 2010, 48(5):351-358.

46. Benitez-Alfonso Y, Jackson D, Maule A: Redox regulation of intercellular transport. Protoplasma 2011, 248(1):131-140

47. Ruan YL, Xu SM, White R, Furbank RT: Genotypic and developmental evidence for the role of plasmodesmatal regulation in cotton fiber elongation mediated by callose turnover. Plant Physio/ 2004, 136(4):4104-4113.

48. Kim JY, Mahe A, Brangeon J, Prioul JL: A maize vacuolar invertase, IVR2, is induced by water stress. Organ/tissue specificity and diurnal modulation of expression. Plant Physiol 2000, 124(1):71-84

49. Mou Z, Wang X, Fu Z, Dai Y, Han C, Ouyang J, Bao F, Hu Y, Li J: Silencing of phosphoethanolamine $\mathrm{N}$-methyltransferase results in temperaturesensitive male sterility and salt hypersensitivity in Arabidopsis. Plant Cell 2002, 14(9):2031-2043.

50. Turoczy Z, Kis P, Torok K, Cserhati M, Lendvai A, Dudits D, Horvath GV: Overproduction of a rice aldo-keto reductase increases oxidative and heat stress tolerance by malondialdehyde and methylglyoxal detoxification. Plant Mol Biol 2011, 75(4-5):399-412.

51. Zhu JK: Salt and drought stress signal transduction in plants. Annu Rev Plant Biol 2002, 53:247-273.

52. Kim TH, Bohmer M, Hu H, Nishimura N, Schroeder Jl: Guard cell signal transduction network: advances in understanding abscisic acid, CO2, and Ca2+ signaling. Annu Rev Plant Biol 2010, 61:561-591.

53. Ackerson RC: Synthesis and movement of abscisic Acid in water-stressed cotton leaves. Plant Physiol 1982, 69(3):609-613.

54. Leung J, Giraudat J: Abscisic Acid Signal Transduction. Annu Rev Plant Physiol Plant Mol Biol 1998, 49:199-222.

55. Yoo CY, Pence HE, Hasegawa PM, Mickelbart MV: Regulation of Transpiration to Improve Crop Water Use. Critical Reviews in Plant Science 2009, 28:410-431.

56. Cho EK, Hong CB: Over-expression of tobacco NtHSP70-1 contributes to drought-stress tolerance in plants. Plant Cell Rep 2006, 25(4):349-358

57. Clement M, Leonhardt N, Droillard MJ, Reiter I, Montillet JL, Genty B, Lauriere C, Nussaume L, Noel LD: The Cytosolic/Nuclear HSC70 and HSP90 Molecular Chaperones Are Important for Stomatal Closure and Modulate Abscisic Acid-Dependent Physiological Responses in Arabidopsis. Plant Physiol 2011, 156(3):1481-1492.

58. Magbool A, Zahur M, Irfan M, Qaiser U, Rashid B, Husnain T, Riazuddin S: Identification, characterization and expression of drought related acrystalline heat shock protein gene (GHSP) from Desi Cotton (Gossypium arboreum L.). Crop Sci 2007, 47:2437-2444.
59. Magbool A, Abbas W, Rao AQ, Irfan M, Zahur M, Bakhsh A, Riazuddin S, Husnain T: Gossypium arboreum GHSP26 enhances drought tolerance in Gossypium hirsutum. Biotechnol Prog 2010, 26(1):21-25.

60. Jang JY, Kim DG, Kim YO, Kim JS, Kang H: An expression analysis of a gene family encoding plasma membrane aquaporins in response to abiotic stresses in Arabidopsis thaliana. Plant Mol Biol 2004, 54(5):713-725.

61. Lee HK, Cho SK, Son O, Xu Z, Hwang I, Kim WT: Drought stress-induced Rma1H1, a RING membrane-anchor E3 ubiquitin ligase homolog, regulates aquaporin levels via ubiquitination in transgenic Arabidopsis plants. Plant Cell 2009, 21(2):622-641.

62. Alexandersson E, Danielson JA, Rade J, Moparthi VK, Fontes M, Kjellbom P, Johanson U: Transcriptional regulation of aquaporins in accessions of Arabidopsis in response to drought stress. Plant J 2010, 61(4):650-660.

63. Rae L: Lao NT. Kavanagh TA: Regulation of multiple aquaporin genes in Arabidopsis by a pair of recently duplicated DREB transcription factors. Planta; 2011

64. Shatil-Cohen A, Attia Z, Moshelion M: Bundle-sheath cell regulation of xylem-mesophyll water transport via aquaporins under drought stress: a target of xylem-borne ABA? Plant J 2011, 67(1):72-80.

65. Hayano-Kanashiro C, Calderon-Vazquez C, Ibarra-Laclette E, Herrera-Estrella L, Simpson J: Analysis of gene expression and physiological responses in three Mexican maize landraces under drought stress and recovery irrigation. PLoS One 2009, 4(10):e7531

66. Jain D, Chattopadhyay D: Analysis of gene expression in response to water deficit of chickpea (Cicer arietinum L.) varieties differing in drought tolerance. BMC Plant Biol 2010, 10:24

67. Lata C, Sahu PP, Prasad M: Comparative transcriptome analysis of differentially expressed genes in foxtail millet (Setaria italica L.) during dehydration stress. Biochem Biophys Res Commun 2010, 393(4):720-727.

68. Molina C, Rotter B, Horres R, Udupa SM, Besser B, Bellarmino L, Baum M, Matsumura $H$, Terauchi $R$, Kahl G, et al: SuperSAGE: the drought stressresponsive transcriptome of chickpea roots. BMC Genomics 2008, 9:553.

69. Uehlein N, Lovisolo C, Siefritz F, Kaldenhoff R: The tobacco aquaporin $\mathrm{NtAQP} 1$ is a membrane $\mathrm{CO} 2$ pore with physiological functions. Nature 2003, 425(6959):734-737.

70. Flexas J, Ribas-Carbo M, Hanson DT, Bota J, Otto B, Cifre J, McDowell N, Medrano $\mathrm{H}$, Kaldenhoff R: Tobacco aquaporin NtAQP1 is involved in mesophyll conductance to CO2 in vivo. Plant J 2006, 48(3):427-439.

71. Heckwolf M, Pater D, Hanson DT, Kaldenhoff R: The Arabidopsis thaliana aquaporin AtPIP1;2 is a physiologically relevant $\mathrm{CO}(2)$ transport facilitator. Plant J 2011, 67(5):795-804

72. Sutka M, Li G, Boudet J, Boursiac Y: Doumas P. Maurel C: Natural variation of root hydraulics in Arabidopsis grown in normal and salt stress conditions. Plant Physiol; 2011

73. Gollery M, Harper J, Cushman J, Mittler T, Mittler R: POFs: what we don't know can hurt us. Trends Plant Sci 2007, 12(11):492-496.

74. Pennisi E: Plant genetics. The blue revolution, drop by drop, gene by gene. Science 2008, 320(5873):171-173.

75. Setter TL, Yan J, Warburton M, Ribaut JM, Xu Y, Sawkins M, Buckler ES, Zhang Z, Gore MA: Genetic association mapping identifies single nucleotide polymorphisms in genes that affect abscisic acid levels in maize floral tissues during drought. J Exp Bot 2011, 62(2):701-716.

76. Des Marais DL, Rausher MD: Escape from adaptive conflict after duplication in an anthocyanin pathway gene. Nature 2008, 454(7205):762-765.

77. Buggs RJ, Zhang L, Miles N, Tate JA, Gao L, Wei W, Schnable PS, Barbazuk WB, Soltis PS, Soltis DE: Transcriptomic shock generates evolutionary novelty in a newly formed, natural allopolyploid plant. Curr Biol 2011, 21(7):551-556.

78. Dong S, Adams KL: Differential contributions to the transcriptome of duplicated genes in response to abiotic stresses in natural and synthetic polyploids. New Phytol 2011, 190(4):1045-1057.

79. Udall JA, Swanson JM, Nettleton D, Percifield RJ, Wendel JF: A novel approach for characterizing expression levels of genes duplicated by polyploidy. Genetics 2006, 173(3):1823-1827

80. Lukens LN, Zhan S: The plant genome's methylation status and response to stress: implications for plant improvement. Curr Opin Plant Biol 2007, 10(3):317-322

81. Wang WS, Pan YJ, Zhao XQ, Dwivedi D, Zhu LH, Ali J, Fu BY, Li ZK: Droughtinduced site-specific DNA methylation and its association with drought tolerance in rice (Oryza sativa L.). J Exp Bot 2011, 62(6):1951-1960. 
82. Campbell BT, Bauer PJ: Genetic Variation for Yield and Fiber Quality Response to Supplemental Irrigation within the Pee Dee Upland Cotton Germplasm Collection. Crop Sci 2007, 47:589-597.

83. Nepomuceno AL, Oosterhuisb DM, Stewartb JM: Physiological responses of cotton leaves and roots to water deficit induced by polyethylene glycol. Environ Exp Bot 1998, 40(1):29-41.

84. Voloudakis AE, Kosmas SA, Tsakas S, Eliopoulos E, Loukas M, Kosmidou K: Expression of selected drought-related genes and physiological response of Greek cotton varieties. FuncPlant Biol 2002, 29(10):1237-1245

85. Wan CY, Wilkins TA: A modified hot borate method significantly enhances the yield of high-quality RNA from cotton (Gossypium hirsutum L.). Anal Biochem 1994, 223(1):7-12.

86. Bachem CW, Oomen RJ, Visser RG: Transcript imaging with CDNA-AFLP: a step-by-step protocol. Plant Mol Biol Rep 1998, 16:157-173.

doi:10.1186/1471-2229-12-90

Cite this article as: Park et al:: Genome-wide identification of differentially expressed genes under water deficit stress in upland cotton (Gossypium hirsutum L.). BMC Plant Biology 2012 12:90.

\section{Submit your next manuscript to BioMed Central and take full advantage of:}

- Convenient online submission

- Thorough peer review

- No space constraints or color figure charges

- Immediate publication on acceptance

- Inclusion in PubMed, CAS, Scopus and Google Scholar

- Research which is freely available for redistribution 